\title{
Appraisal Devices Realizing Attitudes in Barack Obama’s First Inaugural Speech
}

\author{
Aram A Alhabib \\ Department of English Language and Translation, Qassim University \\ PO Box 56241, Qassim, Saudi Arabia \\ E-mail: 411200085@qu.edu.sa
}

Received: August 1, 2020 Accepted: September 19, 2020 Published: October 12, 2020

doi:10.5296/ijl.v12i5.17618

URL: https://doi.org/10.5296/ijl.v12i5.17618

\begin{abstract}
Following Martin and Rose's (2007) Systemic Functional Linguistics (SFL) approach, this paper, adopting qualitative analysis, analyzed Barack Hussein Obama's Inaugural Address "new era of responsibility" from the perspective of Appraisal System. Martin and Rose (2007) divided Appraisal System into three distinct sub-systems: Source (Engagement), Amplification, and Attitude. In the process of detailed analysis, this paper focused on Obama's Attitude, the feelings, and values that are negotiated with the audience (Affect, Judgment, and Appreciation), towards his speech. Analyzing the data that falls under the genre of political discourse, it could be inferred that the address employed three kinds of Attitudes; Affect, Judgment, and Appreciation. The findings of the study revealed that Obama's speech was full of hope and a positive attitude toward the future of the United States. The president used accessible language but still formal; he used affirmative and simple direct sentences in his speech, so he can easily shorten the distance between him and the audience.
\end{abstract}

Keywords: Appraisal system, Inaugural address, Political speech

\section{Introduction}

Discourse analysis cannot be limited to the classification of linguistics forms independent of the functions in which those forms are designed to assist in human affairs (Brown \& Yule, 1983). Therefore, while conducting discourse analysis, we should pay attention to not only the language itself but the information behind it as well. Language is not independently powerful; it obtains power through powerful orators and politicians to inspire and influence the audience toward the intended purposes and meanings (Woods, 2006). As indicated by 
Fowler (1979), political discourse is a kind of discourse, regarded as the product of the political system. It involves a country's internal and external policies. The purpose is to create power through language to realize the political intention of politicians, and this refines why the language utilization of those influential people can be read critically and with analysis (Kazemian \& Hashemi, 2014).

Halliday (2004) addressed that language has three meta-lingual functions, namely, Ideational, Interpersonal, and Textual functions. Arising within the zone of the "interpersonal" social meta-function of language, Appraisal System, which became the basis of this study, is a structure for investigating the tools language employs to evaluate and adapt attitudes adopted by discourse producers. Martin and Rose (2007) divided Appraisal System into three distinct sub-systems: Source (Engagement), Amplification, and Attitude. This research concentrates on President Barack Hussein Obama's Attitude, the feelings adjusted with the audience (Affect, Judgement, and Appreciation) for his speech.

\subsection{Context of the Problem}

Public speaking is a vital means of communication and an effective way of conveying speakers' messages to the public (Yang, 2017). American Presidential Inaugural Address is a kind of political rhetoric that is delivered by the newly elected president on the occasion of inauguration (Yang, 2017). However, for a deep understanding of the speech, people need to learn more in-depth about the language and its function through linguistics. In this respect, the current paper will use Barack Obama's Inaugural Address to unfold the attitudinal resources that are explicitly presented or indirectly implied in his speech and explore how effective the language was to construct a persuasive rhetorical stance.

\subsection{Significance of the Study}

Through the careful and detailed analysis of the attitudinal resources, this research will enrich our understanding of Martin and Rose's (2007) Appraisal System and will add to the body of research on the discourse analysis of political speech. This study provides an opportunity to advance our knowledge more profoundly and comprehensively of grasping the president's Inaugural address; revealing how he used evaluative language resources to coordinate Affect, Judgment, and Appreciation, as well as how effective the language was to construct a persuasive rhetorical stance. Consequently, by examining the speech, people will attain knowledge for a more excellent text perception.

\subsection{Research Questions}

The researcher seeks to address the following questions:

1- How are attitudinal devices employed in Barack Obama's Inaugural Speech?

2- What are the president's evaluative strategies by which he presents himself? e.g., more or less deferential, dominating, authoritative, inexpert, cautious, conciliatory, emotional, impersonal, and so on (White, 2001). 


\subsection{Review of Literature}

\subsubsection{Theoretical Framework}

\subsubsection{Systemic Functional Linguistics (SFL)}

SFL essentially involves how people employ language to perform everyday life and how social worlds are, in exchange, built-in and through language.

SFL essentially involves how people employ language to perform everyday social life and how social worlds are, in exchange, built-in and through language. Despite the complexity of communication in the social context, the basic principles of SFL are simple and have evolved to manage the complexity of the phenomena it describes (Martin \& Rose, 2007). SFL, therefore, concentrates on the analysis of texts, acknowledging the relation of the social context in which they transpire.

SFL, as indicated by Halliday and Matthiessen (2004), perceives language as a social system of linguistic choices that performs three meta-functions: interpersonal, ideational, and textual. Based on these three meta-functions, Martin and Rose (2007) developed six systems: appraisal system, ideational system, conjunction system, identification system, periodicity system, and negotiation system. Systemic Functional Linguistics (SFL) is the substantive father system to the existing and development of the Appraisal framework. It raises the opportunity to analyze linguistic phenomena, referencing language's functional demands by its users, and social functions presented byword in social settings (Hadidi, 2015).

\subsubsection{Appraisal, the System of Expressing Our Feelings and Attitudes}

Developing from the region of the interpersonal social meta-function, Appraisal is a system used to examine the tools that language employs in evaluates attitudes used by discourse generators (Hadidi, 2015). As indicated by White (2001), the origin of Appraisal system arises from work on narrative genres in the late 1980s. The approach emerged from a group of functional linguistics researchers directed by the Professor of the University of Sydney, James Martin. Martin and Rose (2007), indicated that systems that have an interpersonal function analyze how language users employ linguistic choices at their disposal to enact their social relationships and express their feelings and attitudes. Martin and Rose (2007) divided Appraisal System into three distinct sub-systems: Source (Engagement), Amplification, and Attitude.

Attitude, the main focus of this research, is represented by Martin and Rose (2007) as something to do with judging things, people's personality, and their feelings. The evaluation appeared to a text by examining its fulfilment in the sentences. Martin and Rose (2007) classified Attitude into several kinds:

1- Expressing people's feelings (Affect). People can have good or bad feelings; thus, Affect can either be positive or negative. Furthermore, people can explicitly or implicitly show their emotions; therefore, Affect can be exposed directly or indirectly.

2- Judging people's character (Judgement). Martin and Rose (2007) report that Judgement 
can be considered as the regimentation of feeling in texts (about how people should or shouldn't act). They indicated that Judgement's classification should be split into two, Social Esteem (Personal) and Social Sanction (Moral), either explicitly or implicitly.

3- Appreciating things (Appreciation). It is a resource for valuing entities or things. Martin and Rose (2007) indicated that both Judgement and Appreciation refer to the object being evaluated. But the difference is that Judgement is done toward people, whereas Appreciation is done towards things.

\subsubsection{Related Studies}

Several researchers have used Appraisal devices to realize Attitude of different types of genres. Hadidi (2015) investigated Appraisal and Attitude in the stylistic analysis of an English Novel. The study focused on a literary corpus and a stylistic/linguistic analysis as a result. The research result indicated that the Appraisal framework could lead to a deeper general understanding of the English language, the mechanisms of its operations, and various types of discourses.

In a study conducted by Sangka (2017), the researcher used Appraisal Devices to realize Attitude in Michelle Obama's speech towards the candidate in New Hampshire. The survey findings revealed that Michelle Obama gave preferences to positive judgments in her address because she held that Hilary Clinton could be the president of the United States. However, she presented negative judgments and appreciations to assess another candidate, and that was Donald Trump. The study stated that Michelle Obama was an excellent orator with significant capability in public speaking.

In a study conducted by Zhongwen and Siyou (2018), the researchers made a contrastive analysis Based on James Martin's Appraisal Theory between Xi Jinping's and Donald Trump's speeches at World Economic Forum in 2017 and 2018. The purpose of their study was to explore how they convey ideology in their addresses, how they make use of language resources to coordinate emotions, judgments, and appreciation. As well as how they engage and graduate semantic contents, thereby exploring the mutual construction of language and power. Their study's findings revealed that positive words in both speeches related to Attitude are more than negative words. However, as indicated by the researchers Zhongwen and Siyou (2018), Xi Jinping's speech was more from humanity's perspective as a whole. He focused on globalization, which is targeted at global protectionism and populism. Conversely, Donald Trump spoke for the United States, the substance and purpose of his speech were to promote the concept of "American first" and unilateral trade.

A group of studies has mainly focused on the analysis of Barack Obama's Inaugural Speech. In a survey conducted by Iqbal (2013), the researcher examined the presidential speech's language rhetoric. The researcher selected theories of Aristotle's rhetoric, and the genre theory of Campbell and Jamieson are accounted to analyze the rhetorical strategies and genre characteristics of the inaugural address.

Yang (2017) analyzed the interpersonal meta-function of Barack Obama's Inaugural Address from the perspective of Interpersonal Meta-function. The researcher was focusing on Mood 
and Modality system at the level of interpersonal function. The study's findings revealed that the first person's plural forms are mostly used, declarative clauses have an absolute advantage, and the medium and low modal auxiliaries appear most frequently in Obama's address. Another study conducted by Wang (2010) analyzed Barack Obama's presidential speeches based on Critical Discourse Analysis Theory and Systematic Functional Linguistics, from the point of transitivity and modality.

In a study conducted by Rohmawati (2016), the researcher followed the same analysis in investigating the presidential Barak Obama's attitudes, feelings, and values that are negotiated with the audience towards his inaugural speech. The study revealed that positive attitudes in the address were used more than negative attitudes to show optimism towards the obstacles in his country that they would be solved, and the condition of America would be better. It also revealed that Obama was an excellent orator with high capability and a fantastic way of thinking.

\section{Method}

Based on the aspects of this investigation, it is both a qualitative and a descriptive approach in nature. The qualitative approach was used to explain Obama's attitudes recognized in his address, "new era of responsibility". The descriptive method was used to describe the realization of interpersonal meaning in the speech laying on the Appraisal System by Martin and Rose (2007).

\subsection{Instruments}

Considering the data is a famous leader's speech, the type of data is a speech document. The data has obtained from the internet. The researcher undertook several steps to collect the data. First, the researcher listened and watched the recorded video of Obama's inauguration speech. Second, the researcher downloaded the script of Barack Obama's inaugural speech from the internet. Third, the researcher read the speech carefully and repeatedly several times for a complete understanding. Finally, the address has been broken down into several clauses, and the Attitudinal selections within the entire address, their type (e.g., Affect, Judgment or Appreciation), the strategy in their consciousness (Explicit or Implicit), and their Polarity (Positive or Negative), are distinguished by the researcher.

\section{Data Collection and Analysis}

A numerical analysis of the data was conducted after the speech's discursive and linguistic analysis was done. Using Microsoft Word software, the complete number of Attitudinal choices and each mode's occurrences were counted. However, considering the numbers of the evaluative expressions for per mode were not the same, the simple percentages of the whole numbers and events for each mode have been calculated manually for a more prominent analysis. Consequently, the similarities of Type, Polarity, and Strategy between the categories would be more apparent.

These specific two calculation and analysis methods are viewed as adequate for data analysis for this research, and subsequent discussions of the research questions' answers and their 
issues are involved with.

\section{Results and Discussions}

The data analysis results accompanied by related discussions will be presented in this part. This section intended to break up the construction of the inaugural address of Barack Obama, based on the Appraisal devices realizing Attitudes. It explains how the address employs Affect, Judgement, and Appreciation that can indicate its speaker's character, feeling towards the phenomenon, and how practical the language could affect people. Two thousand four hundred four words were found. The complete number of Attitudes among all sentences is 323. It has 50 clauses of Affect (15.47\%), 156 clauses of Judgement (48.29\%), and 117 clauses of Appreciation (36.22\%).

\subsection{Appraisal Devices Used to Realize Attitude of Obama's Inaugural Speech}

\subsubsection{Affect}

While we investigate how people reveal their feeling in the discourse, we observe that they differ in two forms. First, people can have either good or bad feelings; therefore, affect can be positive or negative. Second, people can reveal their feelings directly or implicitly through their behavior; thus, affect can also be expressed directly or implied. However, regarding the direct and implicit representation of feelings, we can recognize that Obama describes his emotion in different ways. For a more precise judgment, look at the excerpts below:

1- My fellow citizens: I stand here today humbled by the task before us, grateful for the trust you've bestowed. (Paragraphs 1-2).

2- On this day, we gather because we have chosen hope over fear, unity of purpose over conflict and discord. (Paragraph 8).

3- All deserve a chance to pursue their full measure of happiness. (Paragraph 10).

4- Our nation is at war against a far-reaching network of violence and hatred. (Paragraph $5)$.

5- We will extend a hand if you are willing to unclench your fist. (Paragraph 25).

From the above excerpts, we can see how Obama placed himself as a humble citizen and addressed his audience as his inseparable compatriots. Excerpt (1) the sentence, "My fellow citizens: I stand here today humbled by the task before us, grateful for the trust you've bestowed." shows that Obama used a positive affect by applying a more citizen-centred attitude, and including all nationalities and ethnicities. Obama used a direct attitude to show his humbleness to the task of the presidency. And he thanked the Americans for the trust of the position. Excerpt (2), the sentence "On this day, we gather because we have chosen hope over fear, unity of purpose over conflict and discord." Obama expressed himself by using a positive, direct affect, to deliver a message to all the people who attended his speech. They have gathered for common reasons; they all desired hope and a better future, rather than fear and conflict. Excerpt (3), the sentence "All deserve a chance to pursue their full measure of happiness." the president used a positive, direct affect, by indicating, far from racism, that all 
people in the whole world deserve to be happy. Excerpt (4), the sentence "Our nation is at war against a far-reaching network of violence and hatred." shows that Obama used a negative effect in both ways, direct and implicit. By saying "at war," the president delivered an implicit negative affect by acknowledging the greed and irresponsibility of some individuals within the society. Furthermore, Obama used the two words "violence and hatred" to indicate a direct negative affect to the current situation of the United States that he seeks to change. Excerpt (5), the sentence "We will extend a hand if you are willing to unclench your fist." the president implied an implicit positive attitude by indicating that the United States is willing to have peace with its enemy if they are stopped their violence first. Based on the general findings of Affect, Obama used positive and direct sentences in his speech more than negatives and implicit ones. Therefore, he can easily shorten the distance between him and the audience.

\subsubsection{Judgment}

Judgment is about evaluating or judging people's attitudes. Judgment can have a positive and negative aspect. Martin and Rose (2007) highlighted that Judgement could be categorized into personal and moral. However, there are two subtypes of Judgement, social esteem and social sanction. Social respect includes admiration and criticism (i.e., dealing with normality, how advanced someone is, capacity, how capable they are, and tenacity, how committed they are). In comparison, social sanction includes praise and condemnation (i.e., dealing with veracity, how truthfully someone is, and propriety, how ethical someone is).

The researcher will start with positive personal Judgement (admiration) and positive moral Judgement (praise). We can view the excerpt:

1- My fellow citizens. (Paragraph 1).

2- It has been the risk-takers, the doers, the makers of things. (Paragraph 11).

3- We remember with humble gratitude those brave Americans. (Paragraph 27).

4- The people, have remained faithful to the ideals of our forebears and true to our founding documents. (Paragraph 3).

5- The selflessness of workers. (Paragraph 28).

Excerpt (1), the sentence "My fellow citizens." shows that Obama used a positive and direct (admiration), i.e., normality, to greet his audience with humbleness, and to indicate that all people are equal to him. Excerpt (2), the sentence "It has been the risk-takers, the doers, the makers of things." delivers a positive attitude (admiration), i.e., capacity, by the president to the people of the United States who have been powerful enough to defend America in the past. Excerpt (3), the sentence "We remember with humble gratitude those brave Americans." shows that Obama used a positive, explicit attitude (admiration), i.e., tenacity, toward the military people in which Obama appreciates and thank them in his speech. Excerpt (4), the sentence "The people, have remained faithful to the ideals of our forebears and true to our founding documents." Obama used words such as faithful and true, to show his positive (praise), i.e., veracity, to the people of the United States who remain faithful and true to their 
country all over the years. Excerpt (5), the sentence "The selflessness of workers." shows the positive (praise), i.e., propriety, of Obama's attitude toward people who have ethics, and they are willing to help each other in the hard times.

Now, the researcher will indicate negative personal judgement (criticism) and negative moral judgement (condemnation). We can see the excerpt:

1- What the cynics fail to understand is that the ground has shifted beneath them. (Paragraph 19).

2- You cannot outlast us, and we will defeat you. (Paragraph 23).

3- On this day, we come to proclaim an end to the petty grievances and false promises. (Paragraph 9).

4- To those leaders around the globe who seek to sow conflict, or blame. (Paragraph 25).

5- A consequence of greed and irresponsibility on the part of some. (Paragraph 5).

Excerpt (1), the sentence "What the cynics fail to understand is that the ground has shifted beneath them." shows that Obama used a negative, explicit attitude (criticism), i.e., normality, toward the people who question and doubt the scale of the United States ambitions. Excerpt (2), the sentence "You cannot outlast us, and we will defeat you." indicates a negative, implicit attitude (criticism), i.e., capacity, to the terrors who want to slaughter the innocents, as Obama said in his address. Excerpt (3), the sentence "On this day, we come to proclaim an end to the petty grievances and false promises." highlights that Obama used a negative, (criticism), i.e., tenacity, to judge the former government by saying that they have given false promises to the people of the United States. Excerpt (4), the sentence "To those leaders around the globe who seek to sow conflict, or blame." indicates a negative, (condemnation), i.e., veracity, by Obama to those leaders who seek to destroy the United States with war and conflicts. Excerpt (5), the sentence "A consequence of greed and irresponsibility on the part of some." delivers a negative, (condemnation), i.e., propriety, by the president to those who took the authority for granted and made irresponsible choices to the people of the United States.

Based on the general findings of Judgement, Obama used positive (admiration) and (praise) in his speech more often than negative (criticism) and (condemnation). Namely because Obama appreciated and admired his people.

\subsubsection{Appreciations}

Martin and Rose (2007) state that Appreciation can be considered the institutionalization of feelings, in the proposition (measures how results and achievements are admired). As Affect and Judgement, Appreciation can positively or negatively evaluate texts and processes, and natural phenomena. The system of Appreciation is realized through three variables: reaction, composition, and valuation. The reaction deals with attention (i.e., impact) and the emotional influence it has on people (i.e., quality). The composition deals with our thoughts of 
proportionality (i.e., balance) and recognizing details (i.e., complexity) in a text. At the same time, valuation deals with our estimation of the text.

The researcher will start with positive Appreciation. We can see the excerpt:

1- This magnificent mall. (paragraph 32).

2- To carry forward that precious gift. (paragraph 10).

3- Unity of purpose over conflict and discord. (paragraph 8).

4- It is precisely this spirit. (paragraph 27).

5- Today I say to you that the challenges we face are real. (paragraph 7).

Excerpt (1), the sentence "This magnificent mall." shows a positive appreciation, i.e., reaction (impact), from the president to the opening place in which the audience had gathered to listen to his speech. Excerpt (2), the sentence "To carry forward that precious gift." highlights a positive appreciation, i.e., reaction (quality), the president encouraged the people of the United States to build a better future for their country. Excerpt (3), the sentence "Unity of purpose over conflict and discord." indicates a positive appreciation, i.e., composition (balance), Obama choose the word, unity, for the people who gathered to listen to his speech to express that they all had chosen peace and unity over conflict and discord. Excerpt (4), the sentence "It is precisely this spirit." shows a positive appreciation, i.e., composition (complexity), the president indicated to the audience that they all need a strong spirit to overcome the upcoming challenges. Excerpt (5), the sentence "Today I say to you that the challenges we face are real." holds a positive appreciation, i.e., valuation, Obama delivered a clear message to the audience, that the United States has real challenges. People should be ready to face these challenges.

Now, the researcher will indicate negative Appreciation found in the speech. We can see the excerpt:

1- Homes have been lost, jobs shed, businesses shuttered. (Paragraph 5).

2- We come to proclaim an end to the petty grievances. (Paragraph 9).

3- Its power to generate wealth and expand freedom is unmatched. (Paragraph 20).

4- Emerged from that dark chapter stronger. (Paragraph 24).

5- We have tasted the bitter swill of civil war. (Paragraph 24).

Excerpt (1), the sentence "Homes have been lost, jobs shed, businesses shuttered." holds a negative appreciation, i.e., reaction (impact), the president informed the audience that the previous crises had a strong negative impact on the United States. Excerpt (2), the sentence "We come to proclaim an end to the petty grievances." indicates a negative appreciation, i.e., reaction (quality), Obama promised the people of the United States that today is the day for new politics, and no more petty grievances and false promises. Excerpt (3), the sentence "Its power to generate wealth and expand freedom is unmatched." highlights a negative 
appreciation, i.e., composition (balance), Obama expressed that the power of the market had no balance between generating wealth and expanding freedom. Excerpt (4), the sentence "Emerged from that dark chapter stronger." shows a negative appreciation, i.e., composition (complexity), Obama indicated that the people of the United States had suffered, and emerged from the civil war stronger than before. Excerpt (5), the sentence "We have tasted the bitter swill of civil war." highlights a negative appreciation, i.e., valuation, the president indicated that the war was bitter and not easy for the people.

Based on Appreciation's general findings, it is evident that the president highly valued his country. It is obtained by using positive, impact, quality, balance, complexity, and valuation in his address.

Table 1. Distribution of type of attitudinal choices in the whole address

\begin{tabular}{llll}
\hline Type & Affect & Judgment & Appreciation \\
\hline Instances & 50 & 156 & 117 \\
\hline Percentages & $15.47 \%$ & $48.29 \%$ & $36.22 \%$ \\
\hline
\end{tabular}

Referring to the findings as a whole, it was determined 323 items of Attitude. They were generally divided into three types: 50 items of Affect, 156 items of Judgement, and 117 items of Appreciation, and each item were divided into positive or negative.

For Affect, 34 positive affects and16 negative Affects, 38 direct Affect, and 12 have implicit. For Judgement, 115 of positive Judgement was found, and 41 of negative ones. For Appreciation, 71 of positive Appreciation was found, and 46 of negative ones. The researcher observed that all clauses have Attitudes. It reveals that the president desired to emphasize each clause. There is only one single emote in this address, i.e., Obama, and the audience who attended the speech.

\section{Conclusion}

The analysis of Barack Obama's Inaugural Address "new era of responsibility" employs three kinds of Attitudes; Affect, Judgement, and Appreciation. In an attempt to answer our first question, "How attitudinal devices are employed in Barack Obama's inaugural speech?" we can conclude that the total number of Attitudes among all clauses is 320. All clause complexes have attitudes. It consists of 50 clauses of Affect $(15.47 \%), 156$ clauses of Judgement (48.29\%), and 117 clauses of Appreciation (36.22\%). Obama used positive Attitudes in presenting his speech more than negative attitudes, mostly because the president was confident that all the obstacles in the United States would be resolved, and the status of America would be more suitable.

In an attempt to answer our second question, "What are the president's evaluative strategies by which he presents himself?" the researcher can conclude that Obama has effectively and creatively delivered his message to the audience by using an accessible language but still a formal one. Throughout the speech, Obama placed himself as a humble citizen and addressed his audience as his inseparable compatriots. The president used affirmative and simple direct sentences in his speech, so he can easily shorten the distance between him and the audience. 


\section{Al Macrothink}

International Journal of Linguistics

ISSN 1948-5425

2020, Vol. 12, No. 5

He also favors the third person plural pronouns (we, us, our) in presenting his speech, in which they play a significant role in creating a sense of unity of the speaker with the audience. Obama had a clear message to be delivered; the message was hope. Despite the problematic situations, i.e., the significant scale of the economic mess that now confronts the United States, together, as a nation, the people of the United States can defeat these tough times. Finally, from the usage of attitudes and proper sentences in the speech; the researcher can draw a conclusion that Barack Hussein Obama is an excellent orator and a good leader with great aptitude and a unique way of thinking.

\section{References}

Brown, G., \& Yule, G. (1983). Discourse analysis. Cambridge: Cambridge University Press. https://doi.org/10.1017/CBO9780511805226

Fowler, R. (1979). Language and control. London: Routledge \& K. Paul.

Hadidi, Y. (2015). Systemic functional linguistics as interpersonal semantics: Appraisal and attitude in the stylistic analysis of an English novel. International Journal of Linguistics, 7(1), 129-148. https://doi.org/10.5296/ijl.v7i1.7199

Halliday, M. A. K. (2004). An Introduction to Functional Grammar. London: Hodder Education.

Halliday, M. A. K., \& Matthiessen, C. M. I. M. (2004). An introduction to functional grammar (3rd ed.). Hodder Arnold Publication.

Iqbal, N. (2013). The Rhetoric of Obama an Analysis of Rhetoric and Genre Characteristics of President Barack Obama's 2013 Inaugural Address. Master of Science (Communication) Thesis, University of Gothenburg.

Kazemian, B., \& Hashemi, S. (2014). Critical discourse analysis of Barack Obama's 2012 speeches: Views from systemic functional linguistics and rhetoric. Theory and Practice in Language Studies, 4(6), 1178-1187. https://doi.org/10.4304/tpls.4.6.1178-1187

Martin, J. R., \& Rose, D. (2007). Working with discourse: Meaning beyond the clause (2nd ed.). Continuum.

Rohmawati, I. (2016). Appraisal devices realizing attitudes in Barack Obama's inaugural speech. Journal for Language and Foreign Language Learning, 5(1), 27-56. https://doi.org/10.21580/vjv5i1859

Sangka, W. (2017). Appraisal theory of attitude in Michelle Obama speech towards presidential candidates of the United States 2016. Bachelor's thesis, UIN Syarif Hidayatullah Jakarta: Fakultas Adab dan Humaniora. Retrieved from http://repository.uinjkt.ac.id/dspace/bitstream/123456789/36690/2/WICAK\%20DEWA20SA NGKA-FAH.pdf

Siyou, Z., \& Zhongwen, P. (2018). Analysis of political language based on appraisal theory: The mutual construction of language and power-taking Xi Jinping and Donald Trump's 


\section{Macrothink}

International Journal of Linguistics

ISSN 1948-5425 2020, Vol. 12, No. 5

speeches at world economic forum as examples. Advances in Social Science, Education and Humanities Research (ASSEHR), 248, 98-110.

Wang, J. (2010). A critical discourse analysis of Barack Obama's speeches. Journal of Language Teaching and Research, 1(3), 254-261. https://doi.org/10.4304/jltr.1.3.254-261

White, R. (2001). Appraisal: An overview. Retrieved from http://www.grammatics.com/appraisal/appraisaloutline/framed/frame.htm

Woods, N. (2006). Describing discourse. New York: Horder Education.

Yang, H. (2017). The interpersonal metafunction analysis of Barack Obamas inaugural address. International Journal of Languages, Literature and Linguistics, 3(1), 27-31. https://doi.org/10.18178/ij1ll.2017.3.1.105

\section{Copyrights}

Copyright for this article is retained by the author(s), with first publication rights granted to the journal.

This is an open-access article distributed under the terms and conditions of the Creative Commons Attribution license (http://creativecommons.org/licenses/by/4.0/) 